\title{
Effect of calcium and/or barium crosslinking on the physical and antimicrobial properties of natamycin-loaded alginate films
}

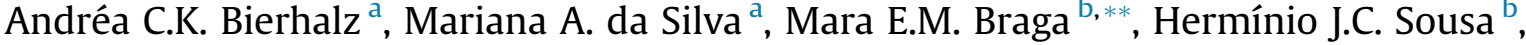 \\ Theo G. Kieckbusch ${ }^{\mathrm{a}, *}$ \\ ${ }^{a}$ DEMBio, School of Chemical Engineering, University of Campinas, UNICAMP, Av. Albert Einstein 500, 13083-852 Campinas, SP, Brazil \\ ${ }^{\mathrm{b}}$ CIEPQPF, Chemical Engineering Department, FCTUC, University of Coimbra, Rua Silvio Lima, Pólo II, Pinhal de Marrocos, 3030-790 Coimbra, Portugal
}

\section{A R T I C L E I N F O}

\section{Article history:}

Received 16 October 2013

Received in revised form

20 January 2014

Accepted 13 February 2014

\section{Keywords:}

Antimicrobial films

Alginate

Natamycin

Crosslinking

Diffusivity

\begin{abstract}
A B S T R A C T
The preparation of alginate films with suitable properties requires a two-step contact with reticulating agents: initially a weakly structured pre-film is formatted which is further crosslinked in a second stage by immersion in a more concentrated solution. The present work evaluated the effects of a combined crosslinking procedure using calcium and barium ions on the physical and morphological properties of alginate-based films containing natamycin as antimicrobial agent. The release behavior of natamycin in water was evaluated as well as the antimicrobial activity against four target microorganisms, which are common cheese product contaminants. Films attributes were affected by the type of ion used in the second stage while the natamycin release rate and the antimicrobial activity were influenced by the ion used in the first stage. Films crosslinked with $\mathrm{Ba}^{2+}$ in the first and $\mathrm{Ca}^{2+}$ in the second stage ( $\mathrm{Ba}-\mathrm{Ca}$ films) exhibited physical properties very similar to films crosslinked with calcium in both stages. Release kinetics of natamycin in water fitted well to Fick's second law diffusional model, with effective diffusivity values ranging from $0.40 \times 10^{-11}$ to $1.74 \times 10^{-11} \mathrm{~cm}^{2} / \mathrm{s}$. Ba-Ca films presented the lowest natamycin diffusion coefficient and the smallest inhibition zone diameter against the four microorganisms tested.
\end{abstract}

(c) 2014 Elsevier Ltd. All rights reserved.

\section{Introduction}

Researches focused on the development of biodegradable films based on polysaccharides and proteins matrices to be used as food protection have grown intensively in recent years. These implements are designed to absorb physical or mechanical impacts and to take advantage of their barrier properties against moisture loss, gases interchanges, oil and fat migration and, therefore, are able to restrain detrimental chemical reactions. In addition, biopolymerbased films are environment-friendly and are suitable materials for incorporating different food additives, such as antimicrobials, which can be gradually released to the food surface preventing contamination by microorganisms and, consequently, extending the shelf-life with a reduction of the amount of additives supplied to the food (Appendini \& Hotchkiss, 2002; Campos, Gerschenson, \& Flores, 2011).

\footnotetext{
* Corresponding author. Tel.: +55 19 35213900; fax: +55 1935213910 .

** Corresponding author.

E-mail addresses: marabraga@eq.uc.pt (M.E.M. Braga), theo@feq.unicamp.br (T. G. Kieckbusch).
}

Alginates are hydrophilic polysaccharides extracted from brown algae (Phaeophyceae). Chemically, they consist of linear copolymers of (1,4)-linked $\beta$-D-mannuronate (M) and $\alpha$-L-guluronate $(G)$ units arranged as homopolymeric blocks (poly-M and poly-G) and blocks with an alternating sequence (Lee \& Mooney, 2012). The most relevant property of alginates is their ability to form water resistant films in the presence of divalent ions by a cross-linking process. Gelation of alginates is conventionally described by the "egg box model", where the divalent ions interact cooperatively with blocks of guluronic units to form ionic bridges between adjacent chains. The reactivity with divalent ions and the subsequent gel formation capacity is a direct function of the average chain length of the $G$ blocks (Lee \& Mooney, 2012). Such crosslinking process leads to an increase in the structural cohesion of the films, resulting in a decrease of permeability to gases, water vapor and solutes (Campos et al., 2011) and of the rate of release of active agents (Al-Musa, Fara, \& Badwan, 1999).

Calcium has been extensively used as the crosslinking ion in the production of alginate films, coatings and beads for food protection and drug delivery applications (Lee \& Mooney, 2012; Rhim, 2004; Tønnesen \& Karlsen, 2002). However, other cations have higher affinity toward alginate and can form stronger gels compared to 
calcium. The affinity of alginate for divalent ions has been shown to decrease in the following order: $\mathrm{Pb}>\mathrm{Cu}>\mathrm{Cd}>\mathrm{Ba}>\mathrm{Sr}>\mathrm{Ca}>\mathrm{Co}$, $\mathrm{Ni}, \mathrm{Zn}>\mathrm{Mn}$ (Mørch, Donati, Strand, \& Skjåk-Bræk, 2006). Since the degree of crosslinking depends on the ability of the ions to diffuse through the film and on their ionic size, barium ions $(0.195 \mathrm{~nm})$, for example, could fill a larger space between the alginate molecules producing a tighter arrangement than with calcium ions $(0.097 \mathrm{~nm})$ (Al-Musa et al., 1999). Furthermore, Ca-alginate films are destabilized in the presence of chelating agents such as phosphates or citrates, which have high affinity for calcium ions, and also by nongelling ions such as sodium and magnesium (Mørch et al., 2006).

Natamycin is an antimicrobial agent widely used in the food industry for the prevention of mould contamination and can be incorporated into Ca-alginate films, maintaining suitable properties (Bierhalz, da Silva, \& Kieckbusch, 2012; da Silva, Bierhalz, \& Kieckbusch, 2012). The film composition as well as the polymeric structure (pore size, packing density and chain flexibility) obtained after the crosslinking process, can exert influence on the diffusion and efficiency of the antimicrobial agent.

The objective of the present study was to evaluate the influence of a combined crosslinking process with calcium and barium ions on the physical and morphological properties of alginate-based films containing natamycin as active agent. In addition, the release behavior of natamycin in water and the diffusion coefficients were evaluated and the antimicrobial activity of active films against four microorganisms commonly found in cheeses was determined.

\section{Materials and methods}

\subsection{Materials}

Medium viscosity sodium alginate (average molecular mass of $1.61 \times 10^{6} \mathrm{Da}$ ), extracted from Macrocystis pyrifera seaweed (Sigma-Aldrich, St. Louis, USA) was used as biopolymer in the films. Calcium chloride dihydrate (Merck, Darmstadt, Germany) and barium chloride dihydrate (Synth, Diadema, Brazil) were used as crosslinking agents and glycerol (Synth, Diadema, Brazil) as plasticizer. Natamycin (Natamax ${ }^{\circledR}, 50 \% \mathrm{w} / \mathrm{w}$ in lactose, Danisco, São Paulo, Brazil), was used as antimicrobial agent.

\subsection{Film preparation}

Alginate films were made by casting in a two-stage crosslinking procedure according to da Silva, Bierhalz, and Kieckbusch (2009) with some modifications. In the first stage, a sodium alginate solution $(1.5 \mathrm{~g} / 100 \mathrm{~mL})$ containing glycerol $(0.6 \mathrm{~g} / \mathrm{g}$ alginate $)$ and natamycin ( $4 \mathrm{~g} / 100 \mathrm{~g}$ alginate) underwent a mild crosslinking by the addition of dilute aqueous $\mathrm{Ca}^{2+}(0.27 \mathrm{~g} / 100 \mathrm{~mL})$ or $\mathrm{Ba}^{2+}(0.12 \mathrm{~g} /$ $100 \mathrm{~mL}$ ) solutions. Aliquots of the solution $(50 \mathrm{~g})$ were poured into square polymethylmethacrilate frames (Plexiglas ${ }^{\circledR}$, Arkema, Colombes, France, $225 \mathrm{~cm}^{2}$ ) and dried in a convection oven (Tecnal, TE 394/2, Brazil) at $40{ }^{\circ} \mathrm{C}$ for about $20 \mathrm{~h}$.

After detaching the dried films from the support, the crosslinking process was complemented in a second stage, by total immersion of the films in $50 \mathrm{~mL}$ of an aqueous $\mathrm{Ca}^{2+}$ solution $(1.2 \mathrm{~g} /$ $100 \mathrm{~mL})$ or $\mathrm{Ba}^{2+}(0.6 \mathrm{~g} / 100 \mathrm{~mL})$ containing glycerol $(3 \mathrm{~mL} / 100 \mathrm{~mL})$ for $10 \mathrm{~min}$. The excess surface liquid was removed by draining and the films were dried in a ventilated ambient for about $5 \mathrm{~h}$, at room temperature $\left(25 \pm 1{ }^{\circ} \mathrm{C}\right)$. All films were conditioned for 3 days at room temperature and 52\% relative humidity inside desiccators before physical characterization. The designation of the films and the respective concentrations of calcium and barium used in the $1 \mathrm{st}$ and 2 nd stage are summarized in Table 1.
Table 1

Film designation and concentration of $\mathrm{Ca}^{2+}$ and $\mathrm{Ba}^{2+}$ ions used in the 1st or 2nd crosslinking stages.

\begin{tabular}{|c|c|c|c|c|}
\hline \multirow[t]{2}{*}{ Designation } & \multicolumn{2}{|c|}{ 1st Stage } & \multicolumn{2}{|c|}{ 2nd Stage } \\
\hline & Ion & $\begin{array}{l}\text { Concentration in the } \\
\text { film forming solution } \\
(\mathrm{g} / 100 \mathrm{~mL})\end{array}$ & Ion & $\begin{array}{l}\text { Concentration in the } \\
\text { reticulation solution } \\
(\mathrm{g} / 100 \mathrm{~mL})\end{array}$ \\
\hline $\mathrm{Ca}-\mathrm{Ca}$ film & $\mathrm{Ca}^{2+}$ & 0.27 & $\mathrm{Ca}^{2+}$ & 1.2 \\
\hline $\mathrm{Ca}-\mathrm{Ba}$ film & $\mathrm{Ca}^{2+}$ & 0.27 & $\mathrm{Ba}^{2+}$ & 0.6 \\
\hline $\mathrm{Ba}-\mathrm{Ca}$ film & $\mathrm{Ba}^{2+}$ & 0.12 & $\mathrm{Ca}^{2+}$ & 0.6 \\
\hline
\end{tabular}

The ion concentration in the film forming solution was defined experimentally as the maximum amount possible to be added to the alginate solution at $70{ }^{\circ} \mathrm{C}$ without the development of a highly viscous solution or local gelation, which hinder smooth casting procedures.

Films crosslinked with $\mathrm{Ba}^{2+}$ ions in both stages were brittle and showed a wrinkly and whitish appearance and, consequently, were not considered in further characterizations.

\subsection{Films characteristics}

Film thickness, solubilized matter in water, water vapor permeability (WVP), mechanical properties, water uptake, opacity and morphological determinations were performed following the same experimental protocol adopted by Bierhalz et al. (2012). In the present work, additional film characterizations were also evaluated and the methodology used is described in detail below.

\subsubsection{Fourier-transform infrared spectroscopy (FTIR)}

FTIR - ATR spectroscopy of the films was performed using a spectrometer (Jasco, model 4000, UK) at 128 scans and with $4 \mathrm{~cm}^{-1}$ resolution, between 400 and $4000 \mathrm{~cm}^{-1}$.

\subsubsection{Sorption isotherms}

Moisture sorption isotherms of the films were determined at $25 \pm 0.1{ }^{\circ} \mathrm{C}$. Film samples were conditioned in small and hermetic chambers $(\sim 100 \mathrm{~mL})$ containing saturated salt solutions prepared with lithium chloride ( $\mathrm{LiCl})$, magnesium chloride $\left(\mathrm{MgCl}_{2} \cdot 6 \mathrm{H}_{2} \mathrm{O}\right)$, potassium carbonate $\left(\mathrm{K}_{2} \mathrm{CO}_{3} \cdot 2 \mathrm{H}_{2} \mathrm{O}\right)$, magnesium nitrate $\left(\mathrm{MgNO}_{3} \cdot 6 \mathrm{H}_{2} \mathrm{O}\right)$, sodium nitrite $\left(\mathrm{NaNO}_{2}\right)$, sodium chloride $(\mathrm{NaCl})$, ammonium sulfate $\left(\left(\mathrm{NH}_{4}\right)_{2} \mathrm{SO}_{4}\right)$, potassium chloride $(\mathrm{KCl})$ and barium chloride $\left(\mathrm{BaCl}_{2} \cdot 2 \mathrm{H}_{2} \mathrm{O}\right)$, in order to obtain $11,32,43,52,64$, $75,80,84$ and $90 \% \mathrm{RH}$ micro-environments, respectively. The samples were weighed until two successive measurements of constant weight were obtained. Equilibrium moisture content $\left(X_{\mathrm{e}}\right)$ was determined by drying the samples in a vacuum oven $\left(105^{\circ} \mathrm{C} /\right.$ $24 \mathrm{~h}$ ). The experimental moisture sorption values obtained, in triplicate, were averaged and fitted by the Guggenheim-Anderson-DeBoer (GAB) model (Equation (1)) (Chirife \& Iglesias, 1978).

$X_{e}=\frac{X_{m} C k a_{w}}{\left(1-k a_{w}\right)\left(1-k a_{w}+C k a_{w}\right)}$

where $X_{e}$ is the equilibrium moisture content on a dry weight basis, $a_{w}$ is the water activity (RH/100), $X_{m}$ is the moisture content related to the water monomolecular layer, $C$ and $k$ are the GAB constants.

\subsubsection{Surface roughness}

The surface roughness $\left(R_{\mathrm{a}}\right)$ of the film surface was determined in triplicate using a portable rugosimeter (Mitutoyo, SJ-210, Japan) with cutoff length (the longest nominal wavelength to be included in roughness) set in $0.8 \mathrm{~mm}$ and total length in $5 \mathrm{~mm}$. 
Measurements were performed on both surfaces of the film $(10 \times 10 \mathrm{~cm})$ in at least ten positions times in each films sample.

\subsubsection{Oxygen permeability}

The oxygen transmission through the films was measured by a Mocon Ox-Tran ${ }^{\circledR} 2 / 20$ apparatus (Modern Controls Inc., Minneapolis, USA) with a coulometric sensor, according to ASTM method D F1927 (ASTM, 2007). The area of permeation was $50 \mathrm{~cm}^{2}$ and the determinations were made at $75 \% \mathrm{RH}$, which was instrumentally controlled. The films were preconditioned at $75 \% \mathrm{RH}$ and $25^{\circ} \mathrm{C}$ for a minimum of $48 \mathrm{~h}$ before testing.

\subsection{Natamycin release}

Natamycin release tests were performed in duplicate by immersing square samples of loaded films $\left(16 \mathrm{~cm}^{2}\right)$ in $25 \mathrm{~mL}$ milliQ water under agitation $(150 \mathrm{rpm})$ at a temperature of $25^{\circ} \mathrm{C}$. At predetermined time periods, an aliquot $(2.0 \mathrm{~mL})$ of the solution was removed, analyzed and then rapidly returned to the sink medium. This procedure was repeated until equilibration. The natamycin concentration in water was determined using a spectrophotometer (Jasco, model 630, Japan) with readings at $319 \mathrm{~nm}$. The mean film thickness was determined before and after each experiment.

\subsection{Diffusion coefficient determination}

Diffusion coefficients were determined from the experimental release test data using the analytical solution of Fick's Second Law for a flat plate (Crank, 1975 , chap. 4). Under the conditions of the experiments and assuming a constant total film thickness, the solution in series, Equation (2), can be used for the fractional natamycin release calculation.

$\frac{M_{t}}{M_{\infty}}=1-\frac{8}{\pi^{2}} \sum_{n=0}^{\infty} \frac{1}{(2 n+1)^{2}} \exp \left(-(2 n+1)^{2} \frac{\pi^{2} D_{1}}{\delta^{2}} t\right)$

where $M_{t}$ and $M_{\infty}$ are the mass of the diffusant released from the film at time $t$ and at infinite time, respectively, $\delta$ is the film thickness measured at the end of the test and $D_{1}$ is the effective diffusivity of natamycin in the film matrix, assumed constant.

For short contact times, when less than $60 \%$ of the solute mass is liberated, a simplified form of Fick's Second Law can be used (Equation (3)):

$\frac{M_{t}}{M_{\infty}}=4 \sqrt{\frac{D_{2} t}{\delta^{2} \tau}}$

The mechanism involved in the diffusion process for a planar system was investigated by fitting the early portion of the release curve $\left(M_{t} / M_{\infty}<0.60\right)$ to a Power Law Model (Equation (4)).

$\frac{M_{t}}{M_{\infty}}=k t^{n}$

where $k$ is a kinetic constant that characterizes the macromolecular arrangement of the polymer matrix, $t$ is the release time and $n$ is a diffusional exponent that typifies release mechanisms (Crank, 1975 , chap. 4).

\subsection{Antimicrobial activity - agar disc diffusion assay}

The antimicrobial effects of the films containing natamycin against Aspergillus niger (ACCT 6275), Penicillium roqueforti (NRLL 849), Penicillium crustosum (IMI 293182) and Penicillium chrysogenum (ATCC 48905) were demonstrated by zone inhibition measurements on solid media (agar diffusion test). The films were cut into discs with $2.5 \mathrm{~cm}$ diameter and sterilized by exposing to UV light $(110 \mathrm{~V}, 254 \mathrm{~nm})$ for $15 \mathrm{~min}$ on each side before the test. A spore suspension $(0.1 \mathrm{~mL})$ containing $10^{6} \mathrm{CFU} / \mathrm{mL}$ of Penicillium-types and $10^{5} \mathrm{CFU} / \mathrm{mL}$ of $A$. niger was spread onto Petri dishes containing approximately $20 \mathrm{~mL}$ of DG18 (A. niger), MEA (P. roqueforti) and PDA media ( $P$. crustosum and $P$. chrysogenum). Film discs were placed aseptically on the surface of the inoculated solid media and the plates were then incubated at $25{ }^{\circ} \mathrm{C}$ for 5 days. After incubation time, the diameters of the inhibitory zones surrounding film discs as well as the contact areas of films with agar surface were then measured with a caliper (Mitutoyo, Brazil). The test was made in triplicate.

\subsection{Statistical analysis}

Analysis of Variance and Tukey Test were used to determine statistically significant differences $(p<0.05)$ among averages, using the Software Statistica V.1.1.5.

\section{Results and discussion}

All alginate films containing natamycin and crosslinked with calcium and/or barium ions by the two-stage method were visually homogeneous, easily handled and showed adequate flexibility. Films crosslinked with barium ions in the 2nd stage (Ca-Ba film) were perceptibly more opaque and were rougher to the touch than films with calcium ion in the final reticulation step.

\subsection{Morphology}

Differences in film morphology due to crosslinking were investigated by scanning electron microscopy (SEM). Micrographs of the surface and cross-section of the films are shown in Fig. 1. Films exhibited a non-uniform structure, with natamycin crystals distributed over the film surface and cross-section. These heterogeneities result from the low water solubility of natamycin $(0.052 \mathrm{mg} / \mathrm{mL})$, which crystallizes during film finishing procedures, as previously shown (Bierhalz, da Silva, de Sousa, Braga, \& Kieckbusch, 2013). The formation of natamycin crystals has been reported by several studies, as for example, in cellulose films (Pires et al., 2008), in methyl cellulose and wheat gluten films (Türe, Eroğlu, Ozen, \& Soyer, 2009) and for alginate and chitosan films (da Silva et al., 2012).

The SEM micrographs of the films crosslinked with barium ions in the 2nd stage ( $\mathrm{Ca}-\mathrm{Ba}$ film) revealed a large number of barium crystals attached to film surface, correlating well with the observed rougher touch. Al-Musa et al. (1999) observed similar conformation and attributed this appearance to a fast surface reticulation with the large-sized barium ions, which hinders the access of the solution remaining $\mathrm{Ba}^{++}$to the film bulk. Furthermore, barium chloride is about two times less soluble in water than calcium chloride, so, the precipitation of the ions on the film surface may have occurred during the drying process.

\subsection{Physical attributes of films}

The alginate films containing natamycin were submitted to physical characterization in order to evaluate the influence of calcium and barium ions on barrier, mechanical and optical attributes. After the second crosslinking stage, all films had an average thickness of $36 \pm 2 \mu \mathrm{m}$.

The values of moisture content, solubilized matter in water and water uptakes are shown in Table 2. The water uptake corresponds to a practical equilibrium condition, which is quickly attained 

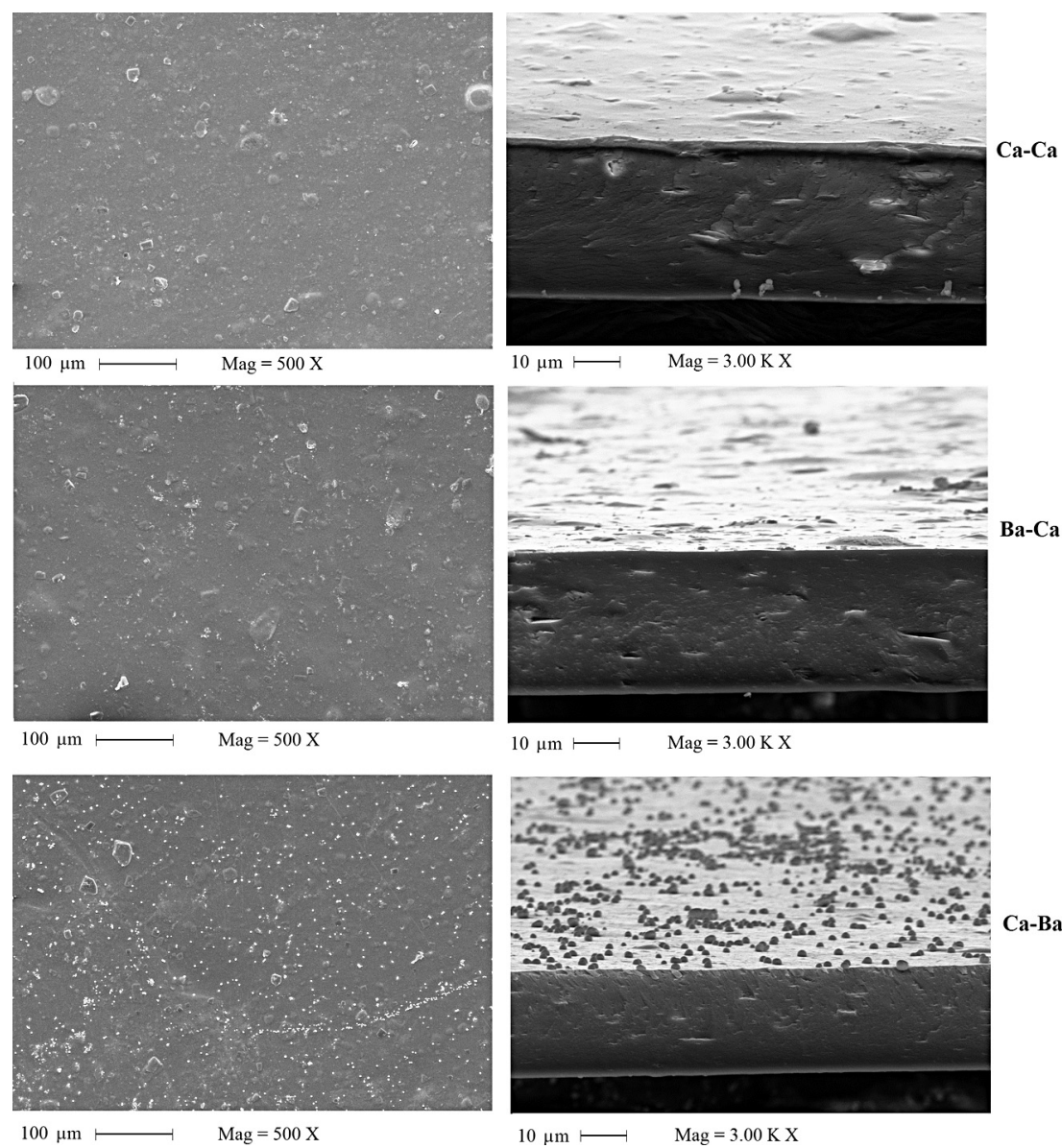

Fig. 1. SEM micrographs for $\mathrm{Ca}-\mathrm{Ca}, \mathrm{Ba}-\mathrm{Ca}$ and $\mathrm{Ca}-\mathrm{Ba}$ alginate films showing films surface (on the left side) and films cross-section (on the right side).

(about 5 min of immersion in water), as already reported by Bierhalz et al. (2012) and da Silva et al. (2009). The moisture content (dry basis) was calculated by GAB equation (see Section 3.4), at a water activity of 0.52 .

The moisture content, the solubilized matter in water and the water uptake decreased significantly for films crosslinked with barium ions in the 2 nd stage ( $\mathrm{Ca}-\mathrm{Ba}$ films) compared to other films. Loh, Wong, and Choong (2012) reported that barium microcapsules

Table 2

Characterization of alginate films crosslinked with $\mathrm{Ca}^{2+}$ and/or $\mathrm{Ba}^{2+}$ ions containing natamycin.

\begin{tabular}{|c|c|c|c|}
\hline \multirow[t]{2}{*}{ Characterization } & \multicolumn{3}{|l|}{ Film } \\
\hline & $\mathrm{Ca}-\mathrm{Ca}$ & $\mathrm{Ba}-\mathrm{Ca}$ & $\mathrm{Ca}-\mathrm{Ba}$ \\
\hline $\begin{array}{l}\text { Moisture content } \\
\qquad\left(\mathrm{g} \mathrm{H}_{2} \mathrm{O} / 100 \mathrm{~g} \text { dry mass }\right)\end{array}$ & $23.63 \pm 1.09^{\mathrm{a}}$ & $24.81 \pm 1.12^{\mathrm{a}}$ & $18.49 \pm 0.38^{b}$ \\
\hline $\begin{array}{l}\text { Solubilized matter in } \\
\quad \text { water }\left(\mathrm{g} \mathrm{H}_{2} \mathrm{O} / 100 \mathrm{~g} \text { film }\right)\end{array}$ & $20.09 \pm 0.64^{\mathrm{a}}$ & $19.09 \pm 0.47^{\mathrm{a}}$ & $17.50 \pm 0.35^{b}$ \\
\hline $\begin{array}{l}\text { Water uptake } \\
\quad\left(\mathrm{g} \mathrm{H}_{2} \mathrm{O} / \mathrm{g} \text { film }\right)\end{array}$ & $0.71 \pm 0.05^{\mathrm{a}}$ & $0.68 \pm 0.03^{\mathrm{a}}$ & $0.49 \pm 0.03^{b}$ \\
\hline $\begin{array}{l}\text { WVP } \\
\quad\left(\mathrm{g} \cdot \mathrm{mm} / \mathrm{m}^{2} \mathrm{~d} \mathrm{kPa}\right)\end{array}$ & $4.14 \pm 0.07^{\mathrm{b}}$ & $4.20 \pm 0.13^{b}$ & $4.97 \pm 0.14^{a}$ \\
\hline $\begin{array}{l}\mathrm{O}_{2} \text { permeability } \\
\quad\left(\mathrm{cm}^{3} \mu \mathrm{m} / \mathrm{m}^{2} \mathrm{~d} \mathrm{kPa}\right)\end{array}$ & $10.3 \pm 1.2^{\mathrm{b}}$ & $9.3 \pm 1.0^{\mathrm{b}}$ & $15.9 \pm 1.4^{\mathrm{a}}$ \\
\hline Opacity (\%) & $48.3 \pm 0.8^{b}$ & $47.2 \pm 0.7^{\mathrm{b}}$ & $54.7 \pm 0.5^{\mathrm{a}}$ \\
\hline Roughness $(\mu \mathrm{m})$ & $0.44 \pm 0.05^{c}$ & $0.48 \pm 0.07^{\mathrm{b}}$ & $0.63 \pm 0.09^{\mathrm{a}}$ \\
\hline Tensile strength (MPa) & $94.10 \pm 5.62^{\mathrm{a}}$ & $94.91 \pm 3.87^{\mathrm{a}}$ & $86.18 \pm 8.92^{a}$ \\
\hline Elongation at break (\%) & $5.38 \pm 0.69^{a}$ & $5.55 \pm 0.34^{\mathrm{a}}$ & $5.59 \pm 0.87^{a}$ \\
\hline
\end{tabular}

Average \pm standard deviation of experimental determinations.

Averages with the same letter, in the same line, indicate no significant differences $(p<0.05)$ by the Tukey Test. had lower swelling degree than calcium microcapsules. According to these authors, this reduction is associated to the "egg-box" structure. Since barium ions are larger than calcium ions, the structures formed can be tighter and, consequently, more water resistant. Darrabie, Kendall, and Opara (2006) reported that the alginate composition and the choice of cations crosslinkers (calcium and barium) have significant influence on bead swelling. They observed that $\mathrm{Ca}$-alginate beads are more prone to swelling than the corresponding Ba-alginate beads, suggesting that $\mathrm{Ca}$ reticulated alginate is more hygroscopic. Mørch et al. (2006) showed that crosslinking of high-G alginates with barium ions results in increased stability and strength, whereas with calcium ions, the process was more efficient for high-M alginates.

The results in Table 2 also indicate that the ion used in the first crosslinking stage does not influence these properties, since the values obtained for $\mathrm{Ca}-\mathrm{Ca}$ and $\mathrm{Ba}-\mathrm{Ca}$ films were equivalent.

The water vapor permeability (WVP) and oxygen permeability values of the films are also displayed in Table 2. In opposition to the properties of water uptake, solubilized matter and moisture content, a comparison between the different formulations indicates that $\mathrm{Ca}-\mathrm{Ba}$ films showed higher WVP and oxygen permeability than $\mathrm{Ca}-\mathrm{Ca}$ and $\mathrm{Ba}-\mathrm{Ca}$ films. This result may be associated to limited bulk crosslinking efficiency, consequence of the difficulty of the large barium ions to cross the compact film surface. Looser internal packing of the film macromolecules increases the free volume of the polymeric structure, increasing permeability.

According to da Silva et al. (2012), WVP is a combined dissolution and diffusion controlled process, governed not only by the concentration and the chemical structure of the components but 
also by chain mobility, which is dependent on intermolecular forces, degree of crosslinking and crystallinity.

The oxygen permeability coefficients of the films were similar to literature values reported for alginate and other polysaccharides films, such as pectin films (Fontes, Ramos, Sivi, \& Queiroz, 2011). In comparison to synthetic polymer films, $\mathrm{Ca}-\mathrm{Ca}$ films had oxygen permeability about 180 times lower than low density polyethylene films and comparable to EVOH and PVDC films, which are commonly used as oxygen barrier (Miller \& Krochta, 1997). Park and Chinnan (1995) also observed that protein and cellulose based edible films have oxygen permeability lower than low density polyethylene and polyvinyl chloride films.

WVP values found in this study were low in comparison to other biodegradable films, such as pectin or methylcellulose (Bierhalz et al., 2012; Fontes et al., 2011), but they were still notably higher than those of most synthetic polymer films. In general, films or coatings containing hydroxyl, ester or other polar groups tend to present low oxygen permeability and high water permeability (McHugh, Avena-Bustillos, \& Krochta, 1993).

The opacity data presented in Table 2 indicate that the three types of films are not transparent. This condition can be attributed to the chemical structure of the natamycin molecule, which contains a hydrophilic and a hydrophobic component. During film finishing procedures, natamycin crystallizes at the film surface, increasing opacity. This trend was previously reported by da Silva, Bierhalz, and Kieckbusch (2011) when natamycin was added to alginate and chitosan films. Alginate films crosslinked with calcium ions without the antimicrobial are transparent, showing only $13 \%$ of opacity (Bierhalz et al., 2012). In films containing immiscible components, the particle size of the dispersed phase and its distribution as well as the differences between the refractive indexes of the phases affect the film transparency (Fabra, Talens, \& Chiralt, 2009).

Values on Table 2 also show that opacity and roughness of the $\mathrm{Ca}-\mathrm{Ba}$ films were higher $(p<0.05)$ compared to the $\mathrm{Ca}-\mathrm{Ca}$ and $\mathrm{Ba}-\mathrm{Ca}$ films. These results correlate well with the SEM micrographs observations that indicated a large quantity of barium particles attached at film surface.

Alginate films without natamycin had a roughness about $60 \%$ lower than active films (data not shown), also due to the low natamycin solubility in aqueous polymeric solution. The increase of film surface roughness after the incorporation of lipids and other hydrophobic compounds have been observed in other studies (Fabra et al., 2009).

Tensile strength and elongation at break were not affected by the different crosslinking agents (Table 2). The low elongation observed for these films can be attributed to the extended chain conformation of alginate which may promote an extension by slippage of chains past each other instead of uncoiling (Gohil, 2011).

\subsection{FTIR-ATR}

The FTIR-ATR spectra obtained for the different films are presented in Fig. 2. Characteristic peaks of alginate can be observed around $3290,1600,1410$, and $1025 \mathrm{~cm}^{-1}$, attributed to $\mathrm{O}-\mathrm{H}, \mathrm{COO}^{-}$ (asymmetric), $\mathrm{COO}^{-}$(symmetric), and $\mathrm{C}-\mathrm{O}-\mathrm{C}$ stretching of biopolymers, respectively (Papageorgiou, Kouvelos, Favvas, \& Sapalidis, 2010). Peaks in the $1200-950 \mathrm{~cm}^{-1}$ region correspond to several vibrations of the carbohydrate ring.

A decrease in the overall absorbance at $3290 \mathrm{~cm}^{-1}$ region can be visualized for the $\mathrm{Ca}-\mathrm{Ba}$ films. This peak appears due to $\mathrm{O}-\mathrm{H}$ stretching vibrations, associated with polar interactions between films components and unbounded water present in the films. The crosslinking with barium promotes an increase in the polymer intermolecular hydrogen bonding and, consequently, the decrease in this $\mathrm{O}-\mathrm{H}$ peak intensity can be related to a reduction of the

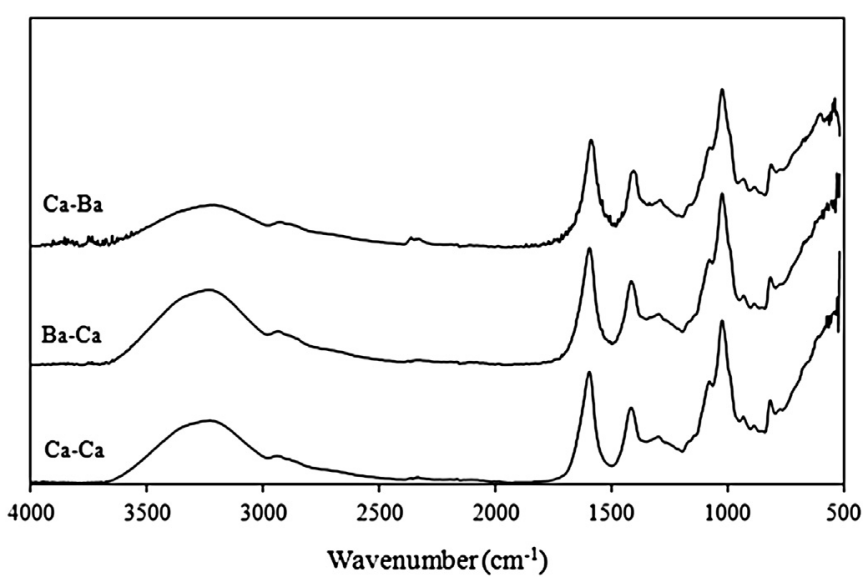

Fig. 2. FTIR-ATR spectra of alginate films.

polymer-water interactions and moisture absorption (Salmieri \& Lacroix, 2006). This behavior is consistent with the moisture content, solubilized matter in water and water uptake data observed for Ca-Ba films in Table 2.

The crosslinking with barium ions in the 2nd stage also promoted shifts in wavenumbers of asymmetric and symmetric $\mathrm{COO}^{-}$ vibrations. For asymmetric $\mathrm{COO}^{-}$peak, the wavenumber was 1598 , 1597 and $1589 \mathrm{~cm}^{-1}$ for $\mathrm{Ca}-\mathrm{Ca}, \mathrm{Ba}-\mathrm{Ca}$ and $\mathrm{Ca}-\mathrm{Ba}$ films, respectively. On the other hand, the symmetric vibration occurred at $1413 \mathrm{~cm}^{-1}$ for $\mathrm{Ca}-\mathrm{Ca}$ and Ba-Ca films, and at $1423 \mathrm{~cm}^{-1}$ for Ca-Ba films. Interactions between alginate and crosslinking agents are mainly characterized by a decrease in the wavenumber of the $\mathrm{COO}^{-}$ asymmetric peak $\left(1600 \mathrm{~cm}^{-1}\right)$; a slight shift of the $\mathrm{COO}^{-}$symmetric peak $\left(1410 \mathrm{~cm}^{-1}\right)$ to higher wavenumbers and a reduction in the peak intensities associated with the free carboxylate groups (1600 and $1410 \mathrm{~cm}^{-1}$ ) and the hydroxyl groups of alginate (Salmieri \& Lacroix, 2006; Tam et al., 2011). For alginate films, Sartori, Finch, Ralph, and Gilding (1997) also observed that $\mathrm{COO}^{-}$symmetrical peak exhibited a shift to higher wavenumbers and a decrease on its intensity by increasing the $\mathrm{Ca}^{2+}$ percentage.

\subsection{Moisture sorption isotherms}

The moisture sorption isotherms showed a sigmoidal shape (Fig. 3) characteristic of Type II isotherms materials, which absorbs

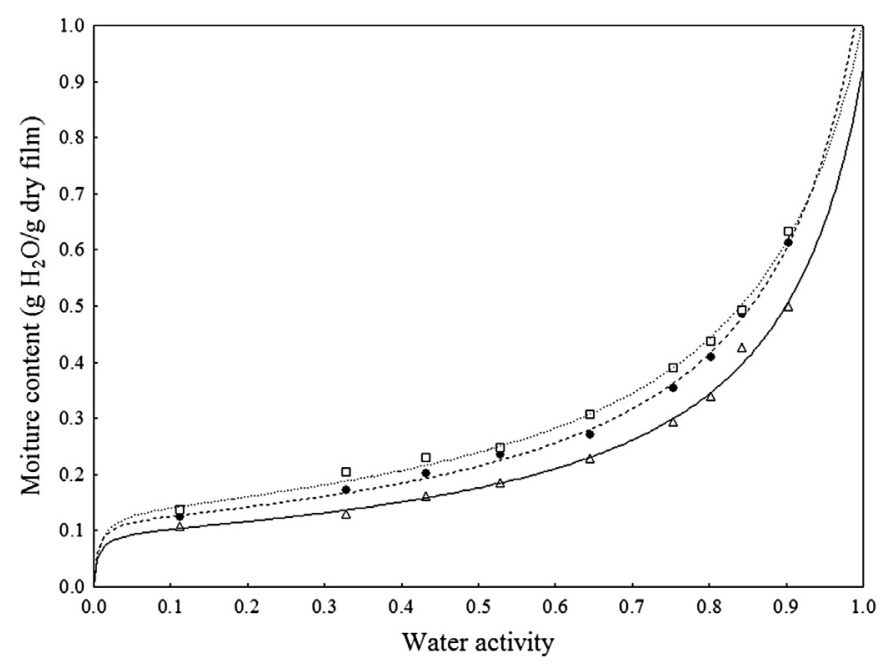

Fig. 3. Moisture sorption isotherms of $\mathrm{Ca}-\mathrm{Ca}(\bullet), \mathrm{Ba}-\mathrm{Ca}(\square)$ and $\mathrm{Ca}-\mathrm{Ba}(\Delta)$ films containing natamycin. The lines correspond to the GAB model fitting (Eq. (1)). 
a relatively small amount of water at low water activities and a large amount at high water activities. This behavior is due to the fact that water affects the films structure acting as a plasticizer. At low relative humidity, the plasticizing effect is very small and the mobility of alginate chains is restricted. As the relative humidity increases, there is an accumulation of water molecules as clusters in the polymeric matrix, followed by swelling, which results in an increasing availability of bonding sites for sorption of water (AlMuhtaseb, McMinn, \& Magee, 2004). This type of isotherm is common for most biopolymer materials and was observed in other studies with alginate films crosslinked with calcium ions (Olivas \& Barbosa-Cánovas, 2008; Rhim, 2004).

The displacement of the curves in Fig. 3 indicates that the moisture sorption isotherms were affected by the crosslinking agent. The results show that $\mathrm{Ca}-\mathrm{Ba}$ films had lower moisture content compared to $\mathrm{Ca}-\mathrm{Ca}$ and $\mathrm{Ba}-\mathrm{Ca}$ films. This same trend was also observed for the calculated monolayer value $\left(X_{\mathrm{m}}\right)$ (Table 3$)$. The monolayer value is related to the maximum amount of water that can be adsorbed in a single layer per gram of dry film and is a measure of number of sorbing sites (Cho \& Rhee, 2002).

The $C$ parameter is related to the difference in chemical potential in the monolayer and the subsequence layers. Unlike the results presented for monolayer value, Table 3 shows that the $C$ parameter was higher for Ca-Ba films. According to Chen, Kuo, and Lai (2013), a low $C$ value implies higher hydrophilicity of the films and less energy is need for the adsorption of water molecules in the active sites. Thus, the results suggest that $\mathrm{Ca}-\mathrm{Ba}$ films are more hydrophobic than $\mathrm{Ba}-\mathrm{Ca}$ and $\mathrm{Ca}-\mathrm{Ca}$ films. The decrease in the monolayer value and the increase in the $C$ parameter are in agreement with findings of other studies involving biopolymers and different plasticizing agents (Cho \& Rhee, 2002). The $k$ parameter of the GAB model was found to be independent of composition.

The high determination values $\left(R^{2}>0.99\right)$ and mean standard deviations (DRM) lower than $5 \%$ shown in Table 3, validated GAB model as a very good representation of the water sorption behaviors of the alginate films containing natamycin.

\subsection{Natamycin release in water}

The natamycin release curves from alginate films manufactured with different crosslinking cations are drawn in Fig. 4. A comparison between the curves indicates that natamycin release was faster for the $\mathrm{Ca}-\mathrm{Ba}$ films. This trend reinforces the hypothesis that the treatment with barium ions in the 2nd stage promotes an inefficient crosslinking inside the film. Al-Musa et al. (1999) studied the release of the drug metoclopramide hydrochloride from alginate films crosslinked with barium, aluminum or calcium ions and observed a faster release for barium-alginate films. The authors also attributed this behavior to the incomplete crosslinking throughout the film.

The slowest release of natamycin was obtained for Ba-Ca films. This result suggests that the crosslinking agent used in the first stage strongly influences the diffusion process, but does not promote changes in the films properties, since the physical characteristics of the $\mathrm{Ca}-\mathrm{Ca}$ and $\mathrm{Ba}-\mathrm{Ca}$ films were very similar. The much slower diffusion found for these films indicates that the interaction

Table 3

GAB fitting parameters $\left(X_{\mathrm{m}}, C, k\right)$; coefficient of determination $\left(R^{2}\right)$ and mean standard deviation (DRM) of alginate films sorption data.

\begin{tabular}{llllll}
\hline Film & $X_{\mathrm{m}}$ & $C$ & $k$ & $R^{2}$ & DRM (\%) \\
\hline Ca-Ca & 0.1292 & 132.97 & 0.8987 & 0.9968 & 2.89 \\
Ba-Ca & 0.1417 & 162.85 & 0.8373 & 0.9953 & 2.01 \\
Ca-Ba & 0.0979 & 260.76 & 0.8824 & 0.9945 & 4.73 \\
\hline
\end{tabular}

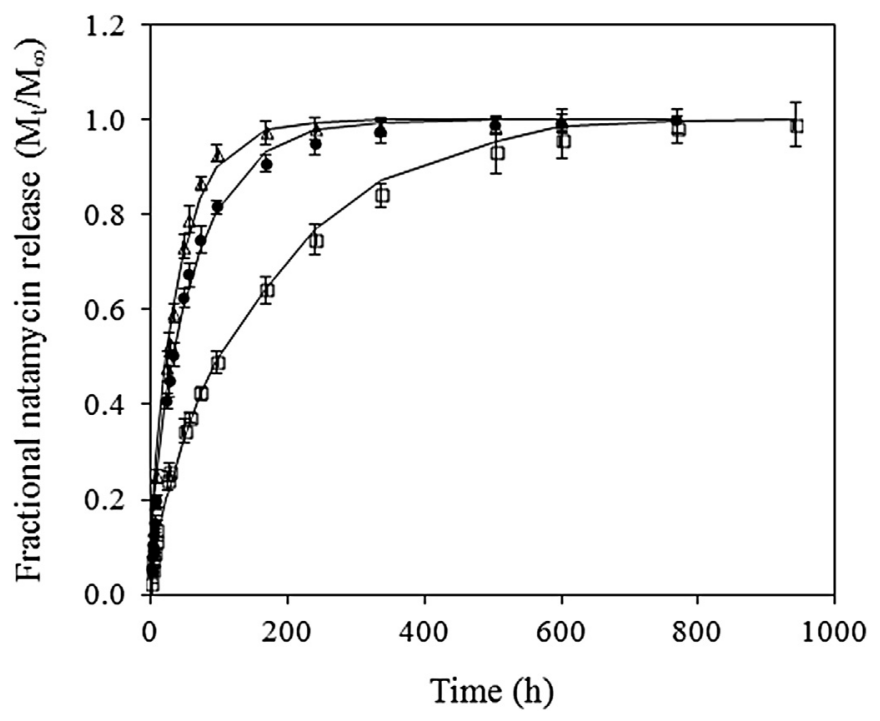

Fig. 4. Fractional natamycin release from: ( $)$ Ca-Ca films; ( $\square$ ) Ba-Ca films and $(\Delta)$ Ca-Ba films. (-) Experimental data fitted by Eq. (2).

between natamycin and alginate chains in $\mathrm{Ba}-\mathrm{Ca}$ films is stronger than in $\mathrm{Ca}-\mathrm{Ca}$ and $\mathrm{Ca}-\mathrm{Ba}$ films. The diffusion of active agent is dependent on their size, shape, polarity characteristics, as well on the chemical structure and the crosslinking level of the films (Zactiti \& Kieckbusch, 2006).

Effective diffusion coefficients of natamycin from alginate films were estimated by adjusting the experimental data to the solution in series of Fick's second law of diffusion (Eq. (2)) using 15 terms in the summation. Initial experimental data $\left(\mathrm{M}_{\mathrm{t}} / \mathrm{M}_{\infty}<0.6\right)$ were also adjusted to the diffusion model for short contact times (semiinfinite solid model) using Eq. (3). These diffusion coefficients, the time to achieve equilibration as well as the determination coefficients $\left(R^{2}\right)$ found for each situation are shown in Table 4 . The diffusivity was significantly lower when barium was used as the crosslinking agent in the first stage and these results correlated well with the release time to equilibration observed for the $\mathrm{Ba}-\mathrm{Ca}$ film curve (Fig. 4).

The diffusion coefficients values found with the two fitting approaches used ( $D_{1}$ for the series solution and $D_{2}$ for the short times solution) were similar and indicate that the process of water uptake and structure relaxation have a limited influence on the mechanism involved in the diffusion process (Zactiti \& Kieckbusch, 2009). In all cases they were several orders of magnitude lower compared to published release data of antimicrobial agents. Franssen, Rumsey,

Table 4

Diffusion coefficients, $D_{1}$ (series solution), $D_{2}$ (short time solution) and natamycin release kinetic parameters by fitting Power Law Model.

\begin{tabular}{llll}
\hline Fitting parameters & Film & & \\
\cline { 2 - 4 } & $\mathrm{Ca}-\mathrm{Ca}$ & $\mathrm{Ba}-\mathrm{Ca}$ & $\mathrm{Ca}-\mathrm{Ba}$ \\
\hline $\begin{array}{c}\text { Diffusion coefficient }\left(D_{1} \times 10^{11}\right) \\
\quad \text { from Eq. }(2)\left(\mathrm{cm}^{2} / \mathrm{s}\right)\end{array}$ & $1.46 \pm 0.26$ & $0.40 \pm 0.02$ & $1.74 \pm 0.10$ \\
$\begin{array}{c}\text { Determination coefficient }\left(R_{D_{1}}^{2}\right) \\
\text { Diffusion coefficient }\left(D_{2} \times 10^{11}\right)\end{array}$ & 0.9971 & 0.9988 & 0.9969 \\
$\quad$ from Eq. $(3)\left(\mathrm{cm}^{2} / \mathrm{s}\right)$ & $1.27 \pm 0.18$ & $0.61 \pm 0.01$ & $1.88 \pm 0.18$ \\
$\begin{array}{c}\text { Determination coefficient }\left(R_{D_{2}}^{2}\right) \\
\text { Diffusion exponent } \\
\quad(n) \text { from Eq. }(4)\end{array}$ & 0.9984 & 0.9972 & 0.9992 \\
$\begin{array}{c}\text { Diffusional constant } \\
\left(k \times 10^{3}\right)\left(\mathrm{s}^{-1}\right)\end{array}$ & $1.9 .10^{-4}$ & $2.6 .10^{-4}$ & $5.4 .10^{-4}$ \\
$\quad$ Determination coefficient $\left(R^{2}\right)$ & 0.9994 & 0.9992 & 0.9989 \\
\hline & & & \\
\hline
\end{tabular}


Table 5

Inhibition zone diameters in agar diffusion test against Aspergillus niger, Penicillium roqueforti, Penicillium chrysogenum and Penicillium crustosum (after 5 days of incubation at $\left.25^{\circ} \mathrm{C}\right)$ exposed to alginate films $\operatorname{discs}(d=2.5 \mathrm{~cm})$.

\begin{tabular}{|c|c|c|c|c|}
\hline \multirow[t]{2}{*}{ Film } & \multicolumn{4}{|c|}{ Diameter of inhibition halos (cm) } \\
\hline & A. niger & P. roqueforti & P. chrysogenum & P. crustosum \\
\hline $\mathrm{Ca}-\mathrm{Ca}^{\mathrm{a}}$ & $5.7 \pm 0.1^{\mathrm{a}}$ & $6.0 \pm 0.1^{\mathrm{a}}$ & $5.7 \pm 0.1^{\mathrm{a}}$ & $5.8 \pm 0.1^{\mathrm{a}}$ \\
\hline $\mathrm{Ba}-\mathrm{Ca}^{\mathrm{a}}$ & $5.0 \pm 0.1^{b}$ & $5.2 \pm 0.1^{\mathrm{b}}$ & $5.3 \pm 0.1^{b}$ & $5.3 \pm 0.1^{\mathrm{b}}$ \\
\hline $\mathrm{Ca}-\mathrm{Ba}^{\mathrm{a}}$ & $5.2 \pm 0.2^{b}$ & $6.0 \pm 0.2^{\mathrm{a}}$ & $5.7 \pm 0.1^{\mathrm{a}}$ & $5.5 \pm 0.2^{\mathrm{ab}}$ \\
\hline $\mathrm{Ca}-\mathrm{Ca}$ control ${ }^{\mathrm{b}}$ & $2.5 \pm 0.0^{c}$ & - & - & $2.5 \pm 0.0^{c}$ \\
\hline $\mathrm{Ba}-\mathrm{Ca}$ control ${ }^{\mathrm{b}}$ & $2.5 \pm 0.0^{c}$ & - & - & $2.5 \pm 0.0^{c}$ \\
\hline $\mathrm{Ca}-\mathrm{Ba}$ control $^{\mathrm{b}}$ & $2.5 \pm 0.0^{c}$ & - & - & $2.5 \pm 0.0^{c}$ \\
\hline
\end{tabular}

Average \pm standard deviation of experimental determinations.

Averages with the same letter, in the same column, indicate no significant differences $(p<0.05)$ with the Tukey Test.

a Samples with natamycin.

b Control samples without natamycin.

and Krochta (2004) determined diffusion coefficients ranging from $3.76 \times 10^{-9}$ to $6.16 \times 10^{-10} \mathrm{~cm}^{2} \mathrm{~s}^{-1}$ of natamycin added to whey protein film, depending on the glycerol concentration in the film matrix. Similarly, Hanusová et al. (2010) obtained diffusion coefficient values in this order of magnitude for pure chitosan films and low density polyethylene film coated with a synthetic lacquer containing natamycin. Values of diffusivity of sorbic acid in alginate films are in the order of $10^{-6} \mathrm{~cm}^{2} / \mathrm{s}$ (Torres \& Karel, 1985) and $10^{-8}$ in wheat gluten films (Redl, Gontard, \& Guilbert, 1996).

A rapid release of the active agent is not desirable since it may promote the solute migration to internal parts of the food, reducing the protection action at the surface (Appendini \& Hotchkiss, 2002). Alternatively, if the release rate is very slow, its inhibitory concentration cannot be reached. Hence, the knowledge of the release rate and, therefore, the diffusivity of the active agents from the film matrix is a determinant factor in the development of antimicrobial films (Zactiti \& Kieckbusch, 2009).

Diffusional exponent values obtained for the films varied from 0.5 to 0.62 , indicating that fickian diffusion is the predominant mechanism. These results indicate that the matrix swelling is able to reach equilibrium much faster than the natamycin release and the major portion of the diffusion process takes place on the already swollen polymeric film.

\subsection{Antimicrobial activity}

The antimicrobial potential activity of alginate films incorporated with natamycin against $A$. niger, $P$. roqueforti, $P$. crustosum and $P$. chrysogenum, which are common cheese product contaminants are shown in Table 5. Antifungal activity was determined by measuring the inhibition zones formed around the films. The values given include the diameter of the samples $(2.5 \mathrm{~cm})$. Films without antimicrobial agent were used as control.

All films containing natamycin inhibited the growth of the target microorganisms. Control films (without natamycin) were able to inhibit the growth of $A$. niger and P. crustosum, as can be seen in Fig. 5. Films without natamycin had no effect on growth of $P$. chrysogenum and roqueforti.

Statistically, a comparison between the performances of the different film crosslinking agents indicates that $\mathrm{Ba}-\mathrm{Ca}$ films developed smaller inhibition zone diameters. These results are in agreement with the findings of diffusivity coefficients. The slower migration of the natamycin to the medium results in a lower

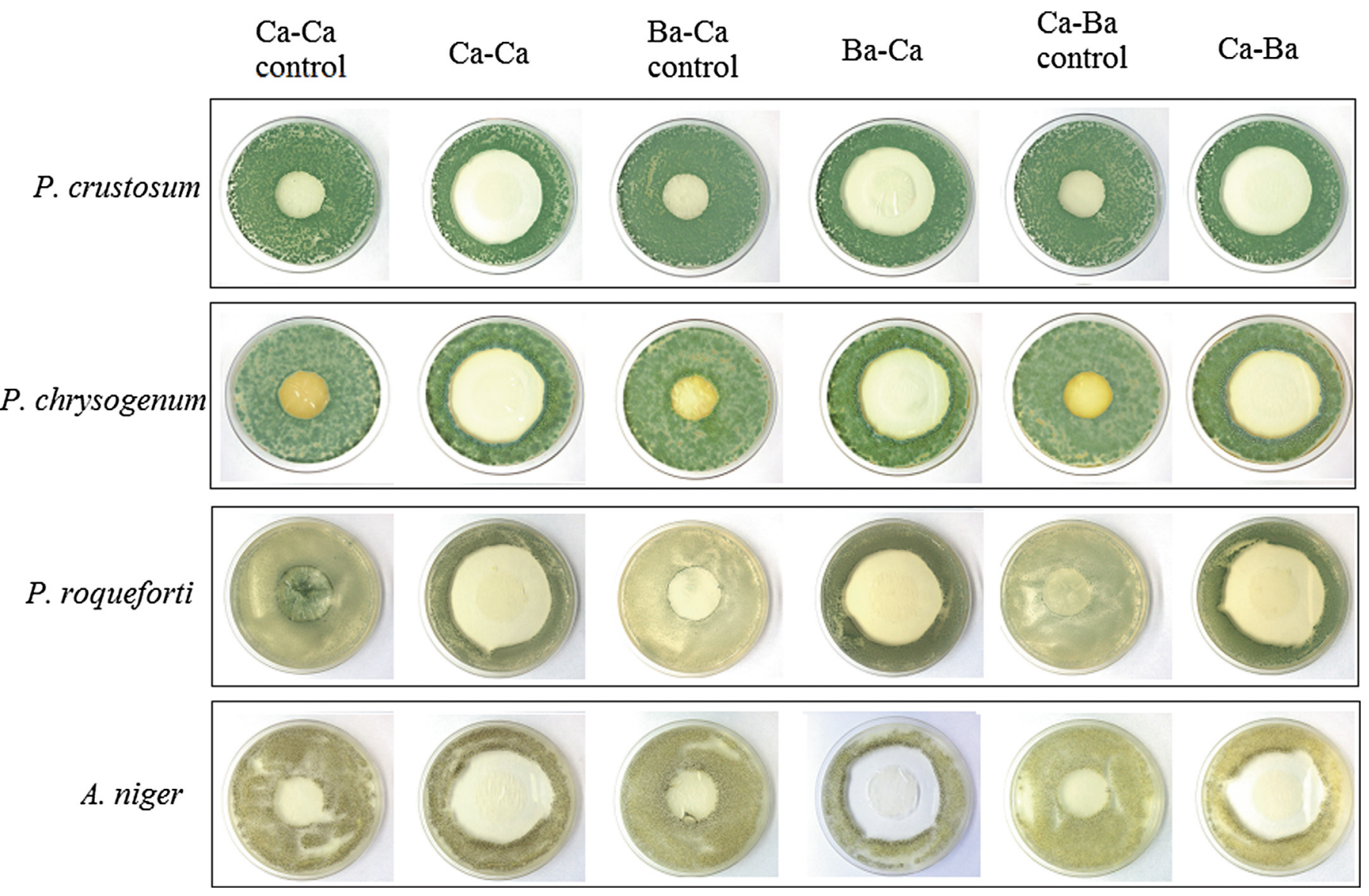

Fig. 5. Antimicrobial effect of alginate films against P. crustosum, P. chrysogenum, P. roqueforti and A. niger after 5 days of incubation at $25{ }^{\circ} \mathrm{C}$. 
microbial growth inhibition ability. da Silva, Iamanaka, Taniwaki, and Kieckbusch (2013) compared the antimicrobial effects of alginate and alginate/chitosan films containing natamycin against Debaromyces hansenii, Penicillium commune and $P$. roqueforti and observed the same correlation between slow release kinetics and smaller inhibition zone diameters.

\section{Conclusions}

This study showed that the divalent cation used as crosslinking agent in the second stage have significant effects on alginate films properties. Films crosslinked with barium in the second stage ( $\mathrm{Ca}-$ Ba) showed lower water uptake, moisture content and solubilized matter in water, but showed higher water vapor and oxygen permeabilities, a consequence of an inefficient crosslinking inside the film structure, which affected film morphology and, consequently, increased the opacity and roughness.

In general, all active films were able to inhibit the growth of $A$. niger, $P$. roqueforti, $P$. commune and $P$. chrysogenum. Release rates of natamycin from the films proved to be strongly dependent on the crosslinking agent used in the first stage of reticulation. Ba-Ca films presented the lowest diffusion coefficient and the smallest inhibition zone diameter against the four microorganisms tested.

\section{Acknowledgments}

The authors acknowledge the CAPES and CNPq for financial support. This work was supported by Programa Ciência 2008 (Portugal) and COMPETE (Portugal) under contract PEst-C/EQB/ UI0102/2011.

\section{References}

Al-Muhtaseb, A. H., McMinn, W. A. M., \& Magee, T. R. A. (2004). Water sorption isotherms of starch powders: Part 1: mathematical description of experimental data. Journal of Food Engineering, 61, 297-307.

Al-Musa, S., Fara, D. A. \& Badwan, A. A. (1999). Evaluation of parameters involved in preparation and release of drug loaded in crosslinked matrices of alginate. Journal of Controlled Release, 57, 223-232.

Appendini, P., \& Hotchkiss, J. H. (2002). Review of antimicrobial food packaging. Innovative Food Science and Emerging Technologies, 3, 113-126.

ASTM. (2007). Standard test method for determination of oxygen gas transmission rate, permeability and permeance at controlled relative humidity through barrier materials using a coulometric detector. In Anmual book of ASTM Standards. Philadelphia: ASTM. Standard F 1927-07.

Bierhalz, A. C. K., da Silva, M. A., \& Kieckbusch, T. G. (2012). Natamycin release from alginate/pectin films for food packaging applications. Journal of Food Engineering, $110,18-25$.

Bierhalz, A. C. K., da Silva, M. A., de Sousa, H. C., Braga, M. E. M., \& Kieckbusch, T. G. (2013). Influence of natamycin loading methods on the physical characteristics of alginate active films. Journal of Supercritical Fluids, 76, 74-82.

Campos, C. A., Gerschenson, L. N., \& Flores, S. K. (2011). Development of edible films and coatings with antimicrobial activity. Food and Bioprocess Technology, 4, $849-875$.

Chen, C.-H., Kuo, W.-S., \& Lai, L.-S. (2013). Development of tapioca starch/decolorized Hsian-Tsao leaf gum-based antimicrobial films: physical characterization and evaluation against Listeria monocytogenes. Food and Bioprocess Technology, 6, 1516-1525.

Chirife, J., \& Iglesias, H. A. (1978). Equations for fitting water sorption isotherms of foods. A Review. Journal of Food Technology, 13, 159-174.

Cho, S. Y., \& Rhee, C. (2002). Sorption characteristics of soy protein films and their relation to mechanical properties. Lebensmittel Wissenschaft und Technologie, 35, $151-157$.

Crank, J. (1975). The mathematics of diffusion (2nd ed.). Oxford: Clarendon Press.

Darrabie, M. D., Kendall, W. F., \& Opara, D. D. (2006). Effect of alginate composition and gelling cation on microbead swelling. Journal of Microencapsulation, 23, 613-621.

Fabra, M. J., Talens, P., \& Chiralt, A. (2009). Microstructure and optical properties of sodium caseinate films containing oleic acid-beeswax mixtures. Food Hydrocolloids, 23, 676-683.
Fontes, L. C. B., Ramos, K. K., Sivi, T. C., \& Queiroz, F. P. C. (2011). Biodegradable edible films from renewable sources-potential for their application in fried foods. American Journal of Food Technology, 6, 555-567.

Franssen, L. R., Rumsey, T. R., \& Krochta, J. M. (2004). Whey protein film composition effects on potassium sorbate and natamycin diffusion. Journal of Food Science, 69, 347-350.

Gohil, R. M. (2011). Synergistic blends of natural polymers, pectin and sodium alginate. Journal of Applied Polymer Science, 120, 2324-2336.

Hanusová, K. Stastná, M., Votavová, L., Klaudisová, K., Dobiás, J., Voldrich, N., et al. (2010). Polymer films releasing nisin and/or natamycin from polyvinyldichloride lacquer coating: nisin and natamycin migration, efficiency in cheese packaging. Journal of Food Engineering, 99, 491-496.

Lee, K. Y., \& Mooney, D. J. (2012). Alginate: properties and biomedical applications. Progress in Polymer Science, 37, 106-126.

Loh, Q. L., Wong, Y. Y., \& Choong, C. (2012). Combinatorial effect of different alginate compositions, polycations, and gelling ions on microcapsule properties. Colloid and Polymer Science, 290, 619-629.

McHugh, H. T., Avena-Bustillos, R., \& Krochta, J. M. (1993). Hydrophilic edible films: modified procedure for water vapor permeability and explanation of thickness effects. Journal of Food Science, 58, 899-903.

Miller, K. S., \& Krochta, J. M. (1997). Oxygen and aroma barrier properties of edible films: a review. Trends in Food Science E Technology, 8, 228-237.

Mørch, Ý., Donati, I., Strand, B. L., \& Skjåk-Bræk, G. (2006). Effect of $\mathrm{Ca}^{2+}, \mathrm{Ba}^{2+}$, and $\mathrm{Sr}^{2+}$ on alginate microbeads. Biomacromolecules, 7, 1471-1480.

Olivas, G. I., \& Barbosa-Cánovas, G. V. (2008). Alginate-calcium films: water vapor permeability and mechanical properties as affected by plasticizer and relative humidity. Lebensmittel-Wissenschaft und Technologie, 41, 359-366.

Papageorgiou, S. K., Kouvelos, E. P., Favvas, E. P., \& Sapalidis, A. A. (2010). Metalcarboxylate interactions in metal-alginate complexes studied with FTIR spectroscopy. Carbohydrate Research, 345, 469-473.

Park, H. J., \& Chinnan, M. S. (1995). Gas and water vapor barrier properties of edible films from protein and cellulosic materials. Journal of Food Engineering, 25, 497-507.

Pires, A. C. S., Soares, N. F. F. Andrade, N. J. Silva, L. H. M. Camilloto, G. P., \& Bernardes, P. C. (2008). Development and evaluation of active packaging for sliced mozzarella preservation. Packaging Technology and Science, 21, $375-383$.

Redl, A., Gontard, N., \& Guilbert, S. (1996). Determination of sorbic acid diffusivity in edible wheat gluten and lipid based films. Journal of Food Science, 61, 116-120.

Rhim, J.-W. (2004). Physical and mechanical properties of water resistant sodium alginate films. Lebensmittel Wissenschaft und Technologie, 37, 323-330.

Salmieri, S., \& Lacroix, M. (2006). Physicochemical properties of alginate/ polycaprolactone-based films containing essential oils. Journal of Agricultural and Food Chemistry, 54, 10205-10214.

Sartori, C., Finch, D. S., Ralph, B., \& Gilding, K. (1997). Determination of the cation content of alginate thin films by FTIR spectroscopy. Polymer, 38, 43-51.

da Silva, M. A., Bierhalz, A. C. K., \& Kieckbusch, T. G. (2009). Alginate and pectin composite films crosslinked with $\mathrm{Ca}^{2+}$ ions: effect of the plasticizer concentration. Carbohydrate Polymers, 77, 736-742.

da Silva, M. A., Bierhalz, A. C. K., \& Kieckbusch, T. G. (2011). Physical-chemical properties of alginate/chitosan composite films containing natamycin as antimicrobial agent. In Proceedings of the 11th International Congress on Engineering and Food (ICEF11), Athens, Greece (p. 6).

da Silva, M. A., Bierhalz, A. C. K., \& Kieckbusch, T. G. (2012). Modelling natamycin release from alginate/chitosan active films. International Journal of Food Science E. Technology, 47, 740-746.

da Silva, M. A., Iamanaka, B. T., Taniwaki, M. H., \& Kieckbusch, T. G. (2013). Evaluation of the antimicrobial potential of alginate and alginate/chitosan films containing potassium sorbate and natamycin. Packaging Technology and Science, $26,479-492$.

Tam, S. K., Dusseault, J., Bilodeau, S., Langlois, G., Hallé, J.-P., \& Yahia, L. (2011). Factors influencing alginate gel biocompatibility. Journal of Biomedical Materials Research Part A, 98A, 40-52.

Tønnesen, H. H., \& Karlsen, J. (2002). Alginate in drug delivery systems. Development and Industrial Pharmacy, 28, 621-630.

Torres, J. A., \& Karel, M. (1985). Microbial stabilization of intermediate food surfaces. III. Effects of surface preservative concentration and surface $\mathrm{pH}$ control on microbial stability of an intermediate moisture cheese analog. Journal of Food Processing and Preservation, 9, 107-119.

Türe, H., Eroğlu, E., Ozen, B., \& Soyer, F. (2009). Physical properties of biopolymers containing natamycin and rosemary extract. International Journal of Food Science E Technology, 44, 402-408.

Zactiti, E. M., \& Kieckbusch, T. G. (2006). Potassium sorbate permeability in biodegradable alginate films: effect of the antimicrobial agent concentration and crosslinking degree. Journal of Food Engineering, 77, 462-467.

Zactiti, E. M., \& Kieckbusch, T. G. (2009). Release of potassium sorbate from active films of sodium alginate crosslinked with calcium chloride. Packaging Technology and Science, 22, 349-358. 